\title{
DIFFERENCES GROWING MEDIA IN AUTOPOT FERTIGATION SYSTEM AND ITS RESPONSE TO CHERRY TOMATOES YIELD
}

\author{
Nurpilihan Bafdal, Sophia Dwiratna, Dwi Rustam Kendarto \\ Department of Agriculture Engineering, Padjadjaran University \\ Jl. Raya Jatinangor Km 21, Sumedang, 45363, Indonesia \\ E-mail korespondensi: nurpilihanbafdal@yahoo.com
}

\begin{abstract}
Hydroponic cultivation system is one solution to overcome the limited agricultural land. This farming system is widely used in farming high-value horticulture, one of them is a cherry tomato plants. The key to success in the hydroponic system is the management of water and nutrients appropriate to the needs of plants. Nevertheless, fertigation system on hydroponic plant cultivation requires a fairly high production costs and dependent on electrical energy for circulation. This study aims to assess the application of fertigation systems that do not use electricity for the circulation of water and nutrients using autopot technology. Fertigation system using this autopot applied to the cherry tomato plants using three combinations of planting medium is husk-compost, husk charcoal-humus and husk-cocopeat with a ratio of 50\%: $50 \%$. The results showed that autopot system capable of supplying the needs of water and plant nutrients to the level of irrigation efficiency is very high also minus consumption of electrical energy. The combination of growing media and compost husk cherry tomato plants to respond favorably with yields of $4.72 \mathrm{~kg} / \mathrm{plant}$.
\end{abstract}

Keywords : Hydroponics; Autopot technology; Growing media; Cherry tomatoes; Fertigation automation

\section{Introduction}

Rainfall in Indonesia is high, ie more than $2000 \mathrm{~mm} /$ year (Nurpilihan and Dwiratna, 2015). The very high potential needs to be exploited through technology support to the sustainability of water resources so that water remains available in every season. The need for water for agriculture in the dry season as the main obstacle in the adequate availability of irrigation water. Necessary water resources management efforts are rainwater harvesting. Rainwater harvesting rainwater is an activity and saves it through a variety of technologies, to meet the needs or human activities(Nurpilihan, Dwiratna and Kendarto, 2015; Nurpilihan, 2016).

Rainwater Harvesting in the agricultural sector can be utilized as a source of irrigation water, especially during the dry season. The utilization of water usage can be optimized so that the necessary technology to support the provision of water in accordance with plant needs through technology autopot. Autopot technology is one of a modern agricultural technology-based self-watering system (Fah, 1996; Nurpilihan, 2016). So that the provision of irrigation water can be done automatically. Autopot fertigation system capable of providing water/nutrients necessary for plant individually in a unique installation system and water provision specific to the plant in an independent and portable devices as shown in Figure 1.

Autopot technology requires organic growing media with certain physical characteristics to optimize plant growth. In principle, autopot fertigation systems using subsurface irrigation system (irrigation capillary) to supply water and nutrients to the plant. Thus the growing media plays an important role in the provision of irrigation water to the plant(Benito et al., 2005; Sailor and Hagos, 2011; Graceson et al., 2014). Planting medium used in the study is the husk charcoal. Reasons for the selection of the planting medium is easily available and the price is relatively cheap. In subsurface irrigation, planting medium is required to have the characteristics of porosity value and a good water holding capacity, so that the water/nutrients can move from the bottom to the root zone. Husk charcoal is essentially a highly porous planting medium but has a low water holding power(Carlile, Cattivello and Zaccheo, 2015). Media are selected based on the ease of acquiring and relatively inexpensive. Based on the description above, the research done to examine the autopot fertigation technology on the cultivation of cherry tomatoes with local growing medium. In addition, this study also aimed to determine the composition of planting medium that gives best results.

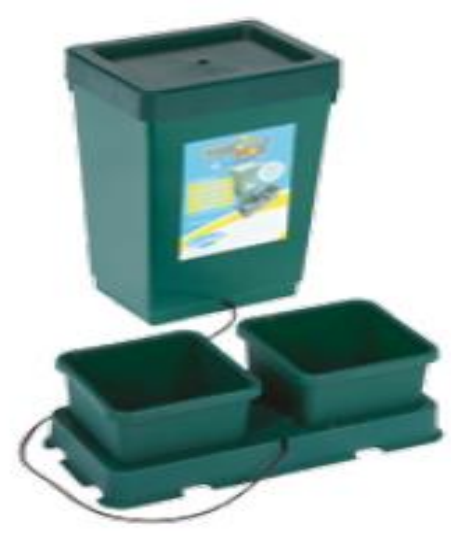

Figure 1. Autopot Device

\section{Methods}

The research was conducted in January to May 2016, at the North Pedca Greenhouse FTIP Unpad, District Jatinangor, Sumedang, West Java province of Indonesia. 
This study was conducted to examine the response of the use of various organic growing medium composition on the growth and productivity of the cherry tomato plants are cultivated using the fertigation system Autopot.

The tools used in the form of fertigation autopot fertigation network, the measuring tool i.e. digital thermohygrometer, lux meter, pan evaporation and water/nutrient quality measuring instrument. While the materials used growing medium (husks charcoal, compost, humus, and cocopeat), tomato seeds, water, and nutrients. The irrigation water used in the form of rainwater harvested from the greenhouse roof and collected in the water tank.

In this study, Autopot technology used in the cultivation of cherry tomatoes using a planting medium that is husks charcoal + humus (M1), husks charcoal + compost (M2), and husks charcoal + cocopeat (M3) with a composition of $50 \%$ : $50 \%$. Observations were made of (1) the physical properties of growing media include BD (Bulk Density), moisture content, specific gravity, porosity, and permeability; (2) in the greenhouse microclimate parameters measured in the form of maximum and minimum humidity, maximum and minimum temperatures and light intensities at $07.00 \mathrm{am}, 12.00 \mathrm{pm}$, and $17: 00 \mathrm{pm}$; (3) response to the use of various compositions of growing media on growth and yield of cherry tomatoes.

\section{Results And Discussion}

Physical Characteristics of Growing Media

The parameters tested in determining the physical characteristics of the planting medium that is associated with BD (Bulk Density), moisture content, specific gravity, porosity, and permeability. Table 1 shows the water content value of the water content of the media M1 (Husks Charcoal + Compost) of $54.9 \%$ by volume, nearly equal to the water content of the planting medium M2 (Husks Charcoal + Humus) amounted to $59.8 \%$. While the water content of the planting medium M3 (Husks Charcoal + Cocopeat) amounted to $73.1 \%$. The high level of water content in the growing media $\mathrm{M} 3$ showed that the addition of cocopeat will increase the amount of water that can be held by the growing medium.

The value of bulk density (bulk density) of the medium M1 amounted to $0.53 \mathrm{~g} / \mathrm{cc}$ then M2 $0.46 \mathrm{~g} / \mathrm{cc}$ and M3 of $0.21 \mathrm{~g} / \mathrm{cc}$. The weight of the contents of the M3 have the value of which is low, it means that a number of solids fewer causing high pore planting medium. Therefore, the water content in M3 was higher than other growing media. This leads to optimal plant growth is not due to a root decay. Inversely proportional to the condition of the M1 and $\mathrm{M} 2$ which have a more optimal growth.

The value of specific gravity (particle density) on the M1 amounted to $1.71 \mathrm{~g} / \mathrm{cc}, \mathrm{M} 21.62 \mathrm{~g} / \mathrm{cc}$, and M3 amounted to $1.48 \mathrm{~g} / \mathrm{cc}$. M1 has a specific gravity at a higher value so that a number of solids to the absorption of nutrients in decomposing nutrients better than the $M 2$ and $M 3$. Specific gravity is also strongly related to the bulk density and total pore space. Table 1 show the value of total pore space planting medium $\mathrm{M} 1$ amounted to $69.3 \%, 71.6 \% \mathrm{M} 2$ and $\mathrm{M} 3$ amounted to $85.8 \%$, from these data we can conclude the planting medium pore space $\mathrm{M} 3$ has great value, it means the ratio of the amount of empty space occupied by more water than growing media M1 and M2. This causes the plant growth in the M3 medium is less than optimal, caused by too much water content contained in the pore spaces of the growing media $\mathrm{M} 3$, and resulted in the decay of plant roots.

Value of the moisture content at different levels of pressure on $\mathrm{M} 1$ is greater than the $\mathrm{M} 2$ and $\mathrm{M} 3$. It shows the state of field capacity to the point of permanent wilting water availability in $\mathrm{M} 1$ more than the $\mathrm{M} 2$ and $\mathrm{M} 3$ that affect productivity and water use fertigation more on the media $M 1$, but in the state of saturation water content of $\mathrm{M} 1$ is lower compared with the $\mathrm{M} 2$ and $M 3$, it may be useful for growing media M1 to avoid the decay of plant roots. Based on the data available, available water value of $\mathrm{M} 1$ at $21.3 \%$, and $\mathrm{M} 2$ by $18.7 \%$ and $\mathrm{M} 3$ by $15.7 \%$. From these data, we can conclude $\mathrm{M} 1$ has an available water content of more than $\mathrm{M} 2$ and $\mathrm{M} 3$ so that the water content available on the M1 can support towards optimum plant growth.

Table 1. Growing Medium Physical Characteristic

\begin{tabular}{llll}
\hline & \multicolumn{3}{c}{ Medias } \\
\cline { 2 - 4 } \multicolumn{1}{c}{ Physical Characteristic } & \multicolumn{1}{c}{ M1 } & M2 & M3 \\
\hline Water Content (\% vol) & 54,9 & 59,8 & 73,1 \\
Bulk Density (g/cc) & 0,53 & 0,46 & 0,21 \\
Particle Density (g/cc) & 1,71 & 1,62 & 1,48 \\
Total Pore (\% vol) & 69,3 & 71,6 & 85,8 \\
Moisture Content (\% vol) & $\mathrm{pF}$ (51.3) & $\mathrm{pF}$ 1(52.5) & $\mathrm{pF}$ 1(63.7) \\
& $\mathrm{pF} 2(44)$ & $\mathrm{pF} 2(40)$ & $\mathrm{pF2(34.3)}$ \\
& $\mathrm{pF} 2.54(38.3)$ & $\mathrm{pF} 2.54(34.6)$ & $\mathrm{pF} 2.54(29.5)$ \\
\hline
\end{tabular}


Fertigation technology autopot operated via smart valve used for opening and closing the irrigation water automatically based on the condition of the water in the pot(Fah, 1996; Nurpilihan, 2016). The water level in the pot is used as a mechanical sensor smart valve to close and open automatically without the assistance of others Figure 2. This is what gives an advantage for the self-watering system for both urban developed as part of urban agriculture. Advantages of self-watering system in agriculture, especially agriculture with high-value commodity crops among others: 1) efficient use of water, 2 ) the provision of water as needed, 3) does not require electrical power / low energy, 4) cost of maintenance, and 5) scheduling independent.

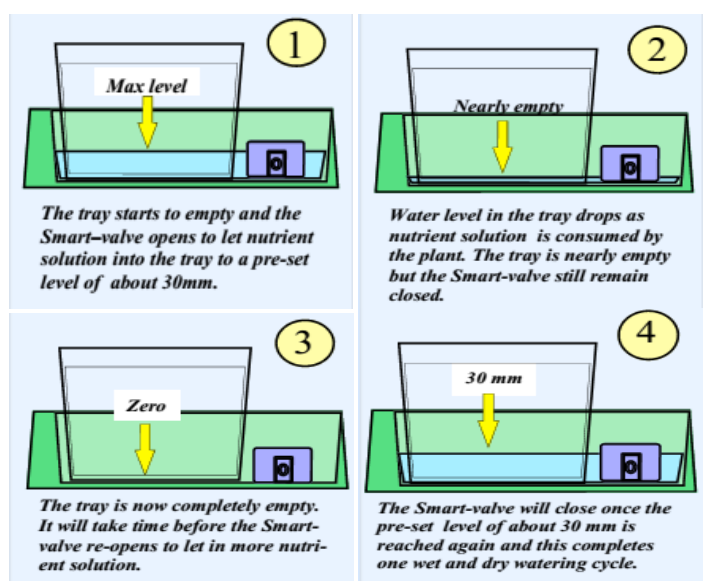

Figure 2. Water circulation of Autopot System(Fah, 1996)

Nutrition plant nutrients stored in a tank then poured into a pot/tray through the main pipe and a lateral pipe which is connected to smart valve installed in the pot as shown in Figure 3.

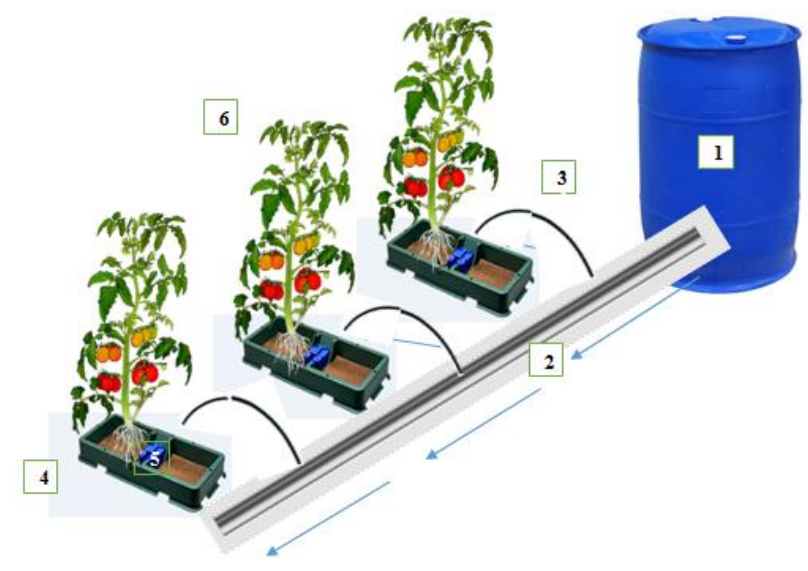

Note :

1. Nutrient Tank; 2. Main Pipe; 3. Lateral Pipe; 4. Autopot; 5. Smart Valve ;6. Cherry Tomatoe

Figur 3. Autopot Working System

In general, irrigation water is circulated in a closed, whereby the water/nutrients are not fed back into the nutrient tank. In the autopot system, water is wasted just through plant transpiration because the pot in a closed condition so that no water is wasted due to evaporation. Therefore, this technology is able to provide a very high irrigation efficiency. A smart valve mounted on autopot allow water diverted will stop once the water level has reached the permitted limit. In smart valve conditions covered by water will stop flowing, until then the smart valve will open back and drain the water when the water/nutrients stored in the pot is reduced / consumables used by the plants, water is lost only in the form of water to meet the needs of any crop consumptive.

\section{Greenhouse microclimate conditions}

Observations microclimate conditions in the greenhouse were conducted to determine the environmental suitability conditions on plant growth(Olley, 2009; Mattson and Peters, 2014). Based on the graph in Figure 4. The intensity of light with an average value for 10 hours at $07.00 \mathrm{am}$ at 8006.90 lux, at noon at $33675.3712 .00 \mathrm{lux}$, and at $17.00 \mathrm{pm}$ today at 2762.22 lux. According to Manurung et al. (2008) optimal tomato growth at an intensity of 482-540 lux * 1000. Olley (2009) stated climate requirements desired by the cherry tomato plants require sunlight is a minimum of 8 hours per day so the plants can grow optimally.

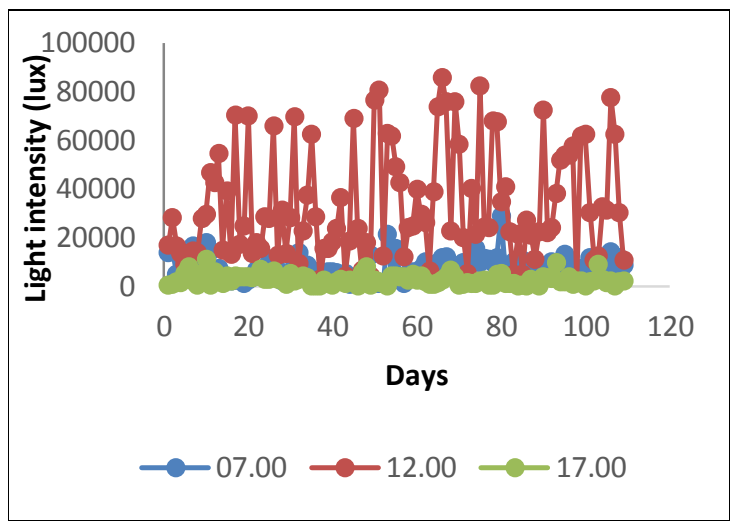

Figure 4. Light Intensity During Cherry Tomatoes Growth

The observation of the environmental temperature can be seen in Figure 5. The data shows the temperature measurement values fluctuating temperatures. This can be overcome by climate modification is the measurement of humidity and temperature stability through fogging technology so that it can be adjusted in order to remain in optimal condition for the growth of plants. The minimum temperature maintained its stability in order to not less than $18^{\circ} \mathrm{C}$, while the maximum temperature is maintained a stability of not more than $30^{\circ} \mathrm{C}$. According to Mattson and Peters (2014) with the hydroponic system can set the environmental conditions such as temperature, relative humidity, and light intensity, even rainfall factor can be eliminated altogether so that the pest attack can be minimized. 


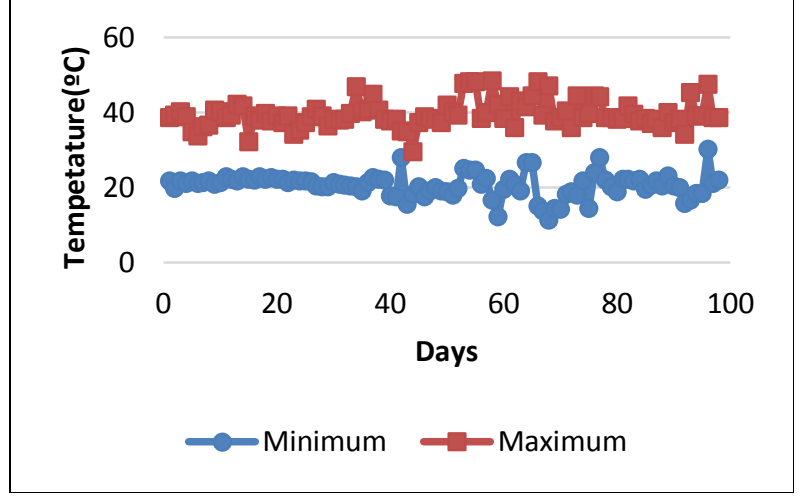

Figure 5. Temperature Condition During Plantation

According Mattson and Peters (2014)for the growth temperature ranges from $25-30^{\circ} \mathrm{C}$ cherry tomato plant with a humidity level of $50-70 \%$. From the measurement data in the field as at present in Figure 5 and Figure 6 note that the maximum value of temperature and humidity that occur in the greenhouse exceeds the range needed, especially during the daytime. In this condition, fogging is done to lower the ambient temperature and humidity increase.

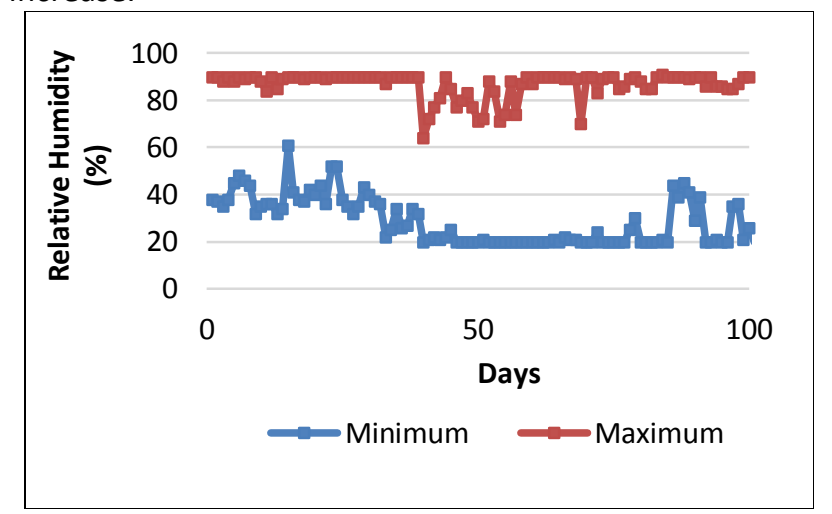

Figure 6. Humidity Condition During Plantation

In addition to the intensity of the sun, the temperature and humidity, in this study also conducted using the evaporation pan evaporation measurements. Figure 7 below shows a comparison of the value of evaporation in the greenhouse and outside the greenhouse is taken from weather stations of Padjadjaran University.

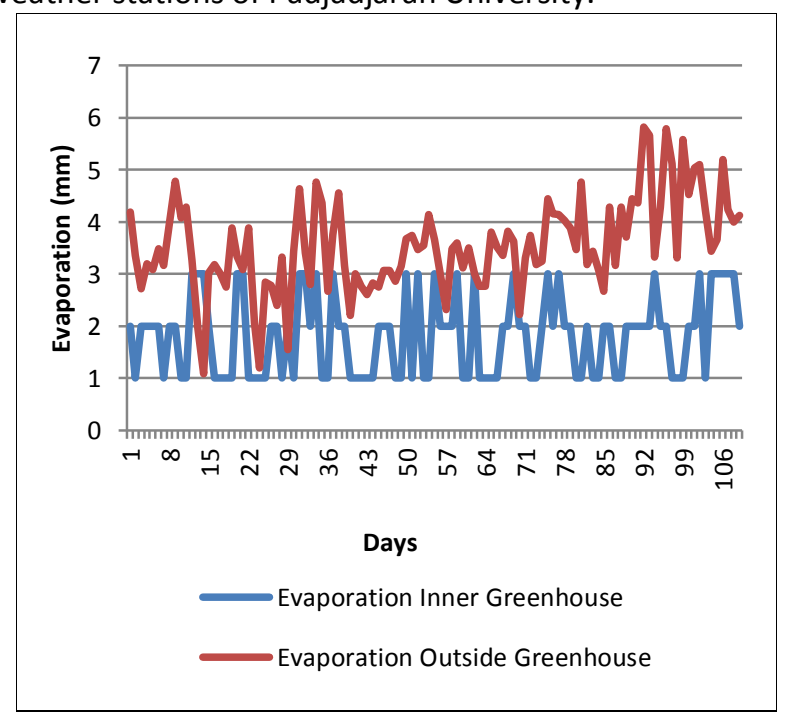

Figure 7. Differences in evaporation values inside and outside the greenhouse

Based on Figure 7, the evaporation that occurs outside the greenhouse is higher than the evaporation in the greenhouse. The average evaporation in the greenhouse was $1.76 \mathrm{~mm}$ / day while the average evaporation outside the greenhouse was $3.6 \mathrm{~mm} /$ day. If the note even though the average temperature in the greenhouse $\left(30.5^{\circ} \mathrm{C}\right)$ higher than the temperature outside the greenhouse $\left(21.2^{\circ}\right.$ C). This indicates that the value of evaporation is not only determined by the temperature but is also influenced by other factors, namely the wind. Jatinangor has a wind speed of less than $4 \mathrm{~m} / \mathrm{sec}$, while in the greenhouse wind factor not taken into account because it was blocked by building the greenhouse.

\section{Cherry Tomato Plant Growth Response}

Parameters used in the plant morphological observation of cherry tomato is the measurements of the plant height and width of the leaves from the early transplanting until near harvest time. Measurement height and width leaves the planting is done once a week. Field measurement results can be seen in Figure 8 below.

Based on observations of plant height as shown in Figure 8 is known that the use of different growth media resulted in a very different response. In the early weeks after planting, high growth charts cherry tomato plants did not show a significant difference between the cherry tomatoes grown in medium M1, M2 and M3. The second week after planting, and so is known that the cherry tomato plants grown with the media M1 provide the best results. But the different conditions are shown in the cherry tomato plants grown in M3 media. Cherry tomatoes grown in M3 media does not give good results, even at the end of week 9 after planting mostly planted withered and dried up.

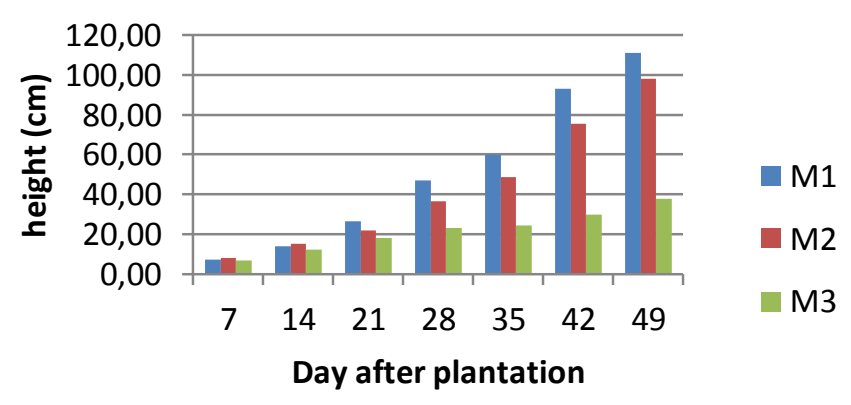

Figure 8. Height of Cherry Tomatoes During Plantation

A similar response occurs in a wide observation of the leaves, which are planted with cherry tomatoes M1 media showed the best results, while the M3 media does not give a good response (Figure 9). In the generative phase subsequently happens to condition the planting medium $\mathrm{M} 3$ are plants that die in the eighth week it begins with a condition of the plant begins to wilt in the sixth week it is 
directly proportional to the analysis of physical characteristics to the growing media M3 occurrence of root rot caused by a number of the moisture content is too high.

Differences in the growth response of cherry tomatoes on different planting media used also resulted in differences in water use as illustrated in Figure 10. Observations on the water consumptive use cherry tomatoes are cultivated done by calculating the total amount of water consumed by the plant for evaporation, and metabolic activity of plant transpiration(Nurpilihan, Dwiratna and Kendarto, 2017).

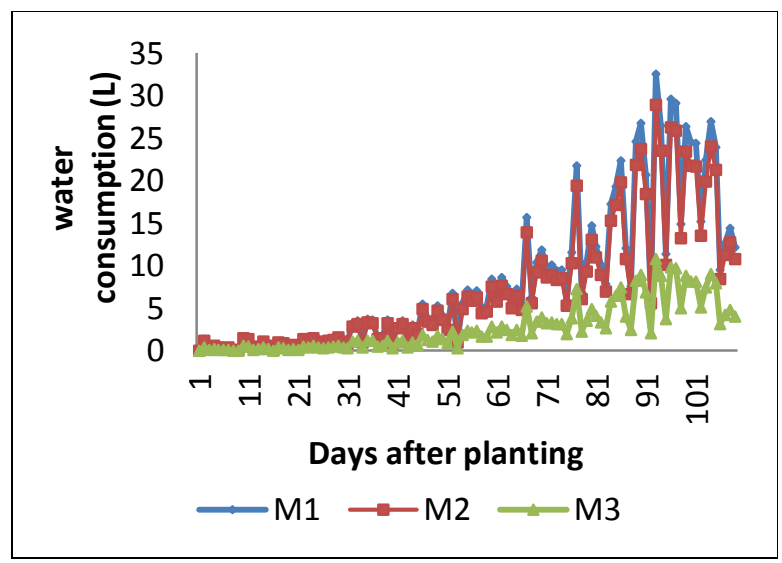

Figure 10. Water Consumptive Use For Differences Growing Media

Figure 10 shows that the total water consumptive use cherry tomatoes at growing media $\mathrm{M} 1$ and $\mathrm{M} 2$ were not significantly different. While the M3 media showed a much different value. Consumption of nutrients and minerals by the roots of plants is done through planting. Thus the root condition will affect nutrient uptake and use of water, if the roots are healthy then the uptake of water and nutrients will not be disturbed so that the growth of plants is also not disturbed. Cherry tomato plant roots are planted using growing media husk charcoal + cocopeat is not well developed, even from week six to week eight most crops suffered root rot, so the plants wither and even death.

\section{Yield of Cherry Tomatoes}

Observations of cherry tomatoes yield that cultivated with autopot technology uses three different kinds of planting medium is done at harvest time. Parameters measured were heavy yields and the number of fruit per plant per one harvest. The average production of cherry tomatoes on the growing media tested can be seen in Table 2 below.

Table 2. Cherry Tomatoes Yield

\begin{tabular}{|l|c|c|r|}
\hline Growing Media & $\mathbf{M}_{\mathbf{1}}$ & $\mathbf{M}_{\mathbf{2}}$ & $\mathbf{M}_{\mathbf{3}}$ \\
\hline Numbers of Fruit per crop & 186 & 113 & 24 \\
\hline Total harvest weght per crop (kg) & 4,72 & 2,48 & 0,45 \\
\hline
\end{tabular}

Based on the value of the cherry tomato plant productivity is the most optimal planting medium $\mathrm{M} 1$, and $\mathrm{M} 2, \mathrm{M} 3$, and most recently, the productivity value of 4.72 $\mathrm{kg}$ in $\mathrm{M} 1, \mathrm{M} 22.48 \mathrm{~kg}$ and $0.45 \mathrm{~kg}$ in the M3, from these data we can conclude M1 productivity higher than other growing medium, it is directly proportional to a number of nutrients and water are absorbed by the growing media M1. According to literature productivity cherry tomatoes, 2 to $3 \mathrm{~kg}$ per plant cherry tomatoes are cultivated using, this figure was still below.

\section{Conclusion}

Based on the physical characteristics of the planting medium. The composition of rice husk + compost media have the most optimal results for cherry tomato plant growth. Productivity is produced from plants cultivated through media compost + husk has a higher value compared to other growing media, the value of the average production at $4.7 \mathrm{~kg}$ per plant. Thus the application of technology autopot the hydroponic cultivation of cherry tomato plant using husk charcoal + compost growing media with a composition of 50\%: $50 \%$ proved to increase productivity with the cherry tomatoes without relying on the use of electrical energy to circulate water and nutrients.

\section{Acknowledment}

The authors would like to thank the Padjadjaran University for providing financial support through Academic Leardeship Grant (ALG) research scheme.

\section{References}

Benito, M., Masaguer, A., De Antonio, R. and Moliner, A. (2005) 'Use of pruning waste compost as a component in soilless growing media', Bioresource Technology, 96(5), pp. 597-603. doi: 10.1016/j.biortech.2004.06.006.

Carlile, W. R., Cattivello, C. and Zaccheo, P. (2015) 'Organic Growing Media: Constituents and Properties', Vadose Zone Journal, 14(6), pp. 1-13. doi: 10.2136/vzj2014.09.0125.

Fah, J. (1996) Hydroponics Made Easy : A Useful Guide for Novice and Intermediate Users of Hydroponics. Bayswater, Vic : Agromatic Corporation Pty Ltd.

Graceson, A., Monaghan, J., Hall, N. and Hare, M. (2014) 'Plant growth responses to different growing media for green roofs', Ecological Engineering, 69, pp. 196200. doi: 10.1016/j.ecoleng.2014.03.067.

Johnson, E. (2014) 'Hydroponic Gardening: Promoting Victory for School Nutrition', Journal of the Academy of Nutrition and Dietetics. Elsevier Inc, 114(9), p. A56. doi: 10.1016/j.jand.2014.06.181.

Mattson, N. S. and Peters, C. (2014) 'A Recipe for Hydroponic Success', Inside Grower, pp. 16-19. Available at: http://www.greenhouse.cornell.edu/crops/factshee ts/hydroponic-recipes.pdf.

Nurpilihan (2016) 'Rainfall Harvesting as Resources of Self Watering Fertigation System with Various Growing 
Medias', International Journal on Advanced Science, Engineering and Information Technology (IJASEIT), 6(5), pp. 787-792. doi: DOI:10.18517/ijaseit.6.5.1158. Nurpilihan, B., Dwiratna, S. and Kendarto, D. R. (2017) 'Impact of Water Use on Paprika ( Capsicum annum ) by Using Fertigation and Autopot System Combined with Numerous Growing Media', Asian Journal of Plant Sciences, 16(3), pp. 149-159. doi: 10.3923/ajps.2017.149.159.

Nurpilihan and Dwiratna, S. (2015) 'Runoff Harvesting as One of Appropriate Technology in Integrated Dry Land Farming', in Proceedings of International Conference on Appropriate Technology Development
(ICATDev) 2015. Bandung, Indonesia, pp. 39-42.

Nurpilihan, Dwiratna, S. and Kendarto, D. R. (2015) 'Runoff Management Technology for Integrated Dry Land Agriculture in Jatinangor Research Center West Java Indonesia', Egyptian Journal Desert Research, 65, pp. $1-11$.

Olley, A. (2009) 'Greenhouse Tomato Production in Cocopeat Turkey', Andrew Olley Consulting, pp. 1-57. Sailor, D. J. and Hagos, M. (2011) 'growing media', Energy \& Buildings, pp. 1-6. doi: 10.1016/j.enbuild.2011.05.014. 